(ISSN: 2582-0370)

\title{
Use of infrared as a complementary treatment approach in medicine and aesthetic medicine
}

Cristiano $\mathrm{L}^{1 *}$

${ }^{1}$ Aesthetic and medical biotechnologies research unit, Prestige Company, Loro Ciuffenna (AR), Italy Corresponding Author: Luigi Cristiano

Address: Aesthetic and medical biotechnologies research unit, Prestige Company, Loro Ciuffenna (AR), Italy; E-mail: luigicristiano@libero.it; prestige.infomed@gmail.com

Received date: 12 October 2019; Accepted date: 22 October 2019; Published date: 29 October 2019

Citation: Cristiano L. Use of infrared as a complementary treatment approach in medicine and aesthetic medicine. Asp Biomed Clin Case Rep. 2019 Oct 29;2(2):77-81.

Copyright (C) 2019 Cristiano L. This is an open-access article distributed under the Creative Commons Attribution License, which permits unrestricted use, distribution, and reproduction in any medium, provided the original work is properly cited.

\begin{abstract}
Infrared radiation has wavelengths between $780 \mathrm{~nm}$ and $1000 \mu \mathrm{m}$. It is well absorbed by living organisms and is perceived as heat. The mechanisms of action of infrared rays on humans are still little known, however their effects on living tissues are well known, particularly useful in the treatment of various diseases and disorders, in the reduction of wound healing times, in weight loss, in non-surgical body remodelling, in photo-rejuvenation, in muscle recovery, in improving sleep quality, in relaxation and in many other applications in medicine, noninvasive aesthetic medicine, beauty, fitness and wellness. This brief communication aims to provide an overview of the use of infrared and related devices in these fields of application, grouping them according to (1) medical applications, (2) non-invasive aesthetic medicine applications and beauty treatments and (3) for home wellness use.
\end{abstract}

\section{Keywords}

Infrared; Near-infrared Rays; Mid-infrared Rays; Far-infrared Rays; FIR Sauna; FIR Blanket; IR Lamps; IR Caps; IR Lipo Laser Paddles; IR Devices

\section{Abbreviation}

IR: Infrared; NIR: Near-infrared Rays; MIR: Mid-infrared Rays; FIR: Far-infrared Rays

\section{Introduction}

The infrared (IR) is an invisible form of electromagnetic radiation with wavelengths between $780 \mathrm{~nm}$ and $1000 \mu \mathrm{m}$ and it is divided into three different bands (according to standard ISO20473:2007): near-infrared, mid-infrared and farinfrared rays. Near-infrared rays (NIR) have the wavelengths between $0.78 \mu \mathrm{m}$ and $3.0 \mu \mathrm{m}$, the midinfrared rays (MIR) have the wavelength between 3.0 $\mu \mathrm{m}$ and $50.0 \mu \mathrm{m}$ and the far-infrared rays (FIR) have the wavelengths between $50.0 \mu \mathrm{m}$ and 1000.0 $\mu \mathrm{m}$
$[1,2]$.

IR rays are absorbed by living organisms [3] through photoacceptor molecules (endogenous chromophores) and are perceived as heat [4]. They show numerous photophysical, photochemical and photobiological responses on the biological tissues with which they come into contact, due to their heatrelated effects and their non-heat-related effects [5-7], although their exact mechanisms of action still need to be clarified. 
Infrared rays are used in all fields of science, from astrophysics to laboratory and analysis instruments, for temperature measurements (thermometers, thermal imaging cameras, night vision goggles, aerial surveys) and are also used for medical or beauty purposes. The present brief communication aims to give an overview of the use of infrared on human beings: 1) in the medical field, 2) in non-invasive aesthetic medicine and in beauty treatments and 3) in home-care uses. All types of medical and aesthetic lasers that emit frequencies in the infrared spectrum, both surgical and non-surgical, are excluded from this report.

\section{Medical applications}

IR rays have been studied and tested for their therapeutic use in the treatment of various diseases and disorders and in reducing wound healing times $[8,9]$.

There are a large number of studies in the scientific literature, mostly referring to the use of FIR, that demonstrate their beneficial use or protective and/or improvement effects in the complementary treatment of cardiovascular diseases (CVD) [10], autoimmune disorders [10], skin problems, such as vesicular eruptive disease of Herpes Simplex Labialis (HSL) [11] and bacterial infections [12], neurodegenerative disorders, such as Alzheimer's and Parkinson's diseases [9,13],chronic health illness [10], such as diabetes mellitus [10], chronic kidney disease [10], chronic pain $[10,14,15]$, chronic fatigue syndrome $[10,16]$ and fibromyalgia $[10,17,18]$. In addition, it has been reported that IR rays can alleviate depression and insomnia [10,19] and they have an antitumor action $[9,20]$.

IR finds application also in rehabilitation medicine with the aim of counteracting muscle contractures and pains and preparing muscles for massages and subsequent physiotherapy treatments.

The devices often used in medical treatments include FIR dry sauna cabins, FIR sauna blankets, IR bands, FIR heat lamps [21]. These devices are used both for general treatments and for localized treatments in specific areas of the body or face in hospitals, private clinics, and specialized medical centers.

\section{Non-invasive aesthetic medicine and beauty care}

IR rays find wide application in non-invasive aesthetic medicine, in beauty and wellness treatments. Appropriate devices are used for various types of treatments on the face, on the body and on the scalp and aimed essentially at stimulating the biological processes of the human tissues, particularly in body toning, for slimming, for non-surgical body remodelling, for non-surgical lymphedema treatment, for hair regrowth, photorejuvenation, in muscle recovery of athletes after training and sports performance and in relaxation treatments $[1,22,23]$. The devices, thanks to the technology with which they are built, their purpose and the possibility of adjusting the emission power, allow safe, painless and noninvasive treatments and are perfectly tolerated by the subject treated.

The devices that are included into these applications are the IR thermal blankets (called also sauna blankets or FIR blankets), the IR lipo laser paddles (called also soft laser), the IR heat lamps, the IR saunas and the IR caps (IR helmets) for hairdressers $[1,2,21]$. These devices allow to perform treatments on the whole body or localized treatments in specific areas, such as the thighs (for example in anti-cellulite treatments), the arms (for example to reduce fatty deposits or the bat wings blemish), the abdomen (to reduce fatty deposits) or scalp (for the treatment of alopecia, receding hairline, balding and thinning hair). In addition, via IR lamps, infrared rays are used to improve the absorption of cosmetic products applied to the skin and for heating hair and scalp i.e. for permanent wave setting and for hair colouring [1].

The IR saunas (and similarly to them the Waon therapy and the Enseki sandbath), but also the IR sauna blankets, have been shown to have a general detoxifying effect and to reduce fatigue in athletes and improve muscle recovery after training sessions $[24,25]$. In addition, they have a general relaxation effect. 
IR devices used in this category of treatments, i.e. for non-invasive aesthetic medicine treatments and beauty treatments, are increasingly used by aesthetic medicine doctors, physio-aesthetic operators, beauticians and sports instructors and are increasingly present in clinics of aesthetic medicine, in physiotherapy and physio-aesthetic clinics, in weight loss centers, in beauty centers, in wellness centers, in spas, in sports centers and gyms.

\section{Use for home-care wellness treatments}

IR rays are also used in everyday life. In fact, they can be integrated into various devices and accessories for home-care uses for the well-being and beauty of the body, as well as for treating pain trigger points and, in general, in local applications to relieve pain and inflammation.

Brushes equipped with infrared LEDs to smooth hair or to slow their loss are hand-held devices increasingly popular in homes as well as IR lamps and IR pens for treating pain trigger points. The former are also used in the home environment on limited areas of the body for the treatment of pain (for example neck pain and low back pain), muscle contractures, photo rejuvenation of the skin and coldrelated disease (ear, nose and throat disorders), while the latter are used for spot applications on the pain trigger points of the body or directly on the acupuncture points.

IR devices belonging to this category are low power devices, easy to use and that can be used by anyone without danger in a domestic environment.

\section{Discussion and conclusion}

Nowadays, the use of infrared is quite widespread even outside medical practice, i.e. in beauty centers, in slimming centers, in gyms up to the house of each of us. This is due to the wide range of tools and technologies with different purposes of use that is therapeutic or aesthetic or aimed at wellness.

Although the precise mechanisms of action are not yet clear, IR rays act on the body through molecules and macromolecules, called photoacceptors. The interaction between living tissues and IR determines the development of heat within the tissues themselves. This heat does not derive from the heating of the air, but rather from the absorption of the IR radiation by the photoacceptors and is called "endogenous heat" because it develops in the tissues that receive the IR rays [1].

These interactions determine the development of what are called heat-related effects, such as the vasodilatation of the capillaries, and explains the direct effects of the infrared action on the human body, which can be grouped into (1) stimulation of the peripheral circulation, which leads to improved tissue perfusion and oxygenation and so to metabolism reactivation; (2) anti-age and detoxifying action, with removal of free radicals and metabolic waste both from the extracellular environment (interstitial fluids) and from the intracellular environment, through the movement of intercellular liquids; (3) draining action, with reduction of lymphatic stasis in the tissues and edema; (4) toning action, with an increase in skin elasticity and a reduction in fat mass; (5) analgesic action on nerve endings and on muscle tissue, which leads to pain reduction and improvement of muscle recovery and sleep quality.

The heat-related effects are accompanied by nonheat-related effects, which bring together all the photochemical, photophysical and photobiological reactions and adaptations that follow the interaction of the photo-acceptors with the infrared rays, which are converted into biological signals, including the activation of pathways that lead to the activation of transcription factors that in turn lead to the activation of specific cellular genes and the consequent modification of the transcriptome $[1,26,27]$.

It is thanks to their constellation of effects that the IR radiation find such a wide application (1) in the complementary therapy of various disorders and pathologies in the medical field, (2) in non-invasive aesthetic medicine, (3) for beauty and wellness treatments, (4) for muscle recovery in sports and professional athletes, (5) to treat minor disorders or blemishes in home-care uses. In addition, it is interesting to report how the action of a single 
infrared session has positive effects up to the next 48 hours $[28,29]$. Beyond the scheduling of the sessions, this fact is very important in the design of routes aimed at slimming and firming the body in order to combine infrared sessions with proper nutrition and with appropriate physical activity to improve and speed up the results of non-invasive aesthetic medicine, but also of beauty and sports improvement paths.

In conclusion, IR rays have wide applications both medical and non-medical, for the face and body, for the treatment of various diseases and disorders and for non-invasive aesthetic applications and, in general, for individual well-being. This happens because the infrared rays interact very well with living tissues and are absorbed by photoaccepting molecules and biological structures. Their effects on the human body are very well known but their precise mechanisms of action are still to be highlighted more clearly.

\section{Declaration of interests}

The author is employed in the Prestige Company and has received a salary also for the research activities for the preparation of this brief communication.

\section{References}

[1] Cristiano L. Use of infrared-based devices in aesthetic medicine and for beauty and wellness treatments. Infrared Physics and Technology. 2019;102:102991.

[2] Cristiano L, (eds). Tecnologie in estetica Apparecchiature per trattamenti viso e corpo in cabina. Tricase: Youcanprint, 2018.

[3] Xiao-Feng P, Bo D, He-Lan X; Guo-Ping C. The investigation of property of radiation and absorbed of infrared lights of the biological tissues. J Infrared Millim Terahertz Waves. 2010;31(4):521-32.

[4] Schieke SM, Schroeder P, Krutmann J. Cutaneous effects of infrared radiation: from clinical observations to molecular response mechanisms. Photodermatol Photoimmunol Photomed. 2003 Oct;19(5):228-34. [PMID: 14535893]

[5] Xiao-feng P, An-ying Z. Mechanism and properties of non-thermally biological effect of the millimeter waves. Int J Infrared Millim Waves. 2004 Mar;25(3):531-52.

[6] Xiao-feng P, An-ying Z. Mechanism of thermally biological effects of the millimeter waves and its properties. Int J Infrared Millim Waves. 2003 Nov;24 (11):1899-12.

[7] Xiao-feng P. Thermally biological effects and its medical functions of the infrared rays absorbed by living systems. Int J Infrared Millim Waves. 2002 Mar;23(3):375-91.

[8] Hsu YH, Lin YF, Chen CH, Chiu YJ, Chiu HW. Far infrared promotes wound healing through activation of Notch1 signaling. J Mol Med (Berl). 2017 Nov;95(11):1203-13. [PMID: 28831511]

[9] Tsai SR, Hamblin MR. Biological effects and medical applications of infrared radiation. J Photochem Photobiol B. 2017 May;170:197-207. [PMID: 28441605]

[10] Shui S, Wang X, Chiang JY, Zheng L. Far-infrared therapy for cardiovascular, autoimmune, and other chronic health problems: A systematic review. Exp Biol Med (Maywood). 2015 Oct;240(10):1257-65. [PMID: 25716016]

[11] Hargate G. A randomised double-blind study comparing the effect of 1072-nm light against placebo for the treatment of herpes labialis. Clin Exp Dermatol. 2006 Sept;31(5):638-41. [PMID: 16780494] [12] Lee SY, Seong IW, Kim JS, Cheon KA, Gu SH, Kim $\mathrm{HH}$, Park KH. Enhancement of cutaneous immune response to bacterial infection after low-level light therapy with $1072 \mathrm{~nm}$ infrared light: a preliminary study. J Photochem Photobiol B. 2011 Dec 2; 105(3):175-82. [PMID: 21955546]

[13] Johnstone DM, Moro C, Stone J, Benabid AL, Mitrofanis J. Turning On Lights to Stop Neurodegeneration: The Potential of Near Infrared Light Therapy in Alzheimer's and Parkinson's Disease. Front Neurosci. 2016 Jan;9:500. [PMID: 26793049] [14] Gale GD, Rothbart PJ, Li Y. Infrared therapy for chronic low back pain: A randomized, controlled trial. Pain Res Manage. 2006;11(3):193-96. [PMID: 16960636]

[15] Masuda A, Koga Y, Hattanmaru M, Minagoe S, Tei C. The effects of repeated thermal therapy for patients with chronic pain. Psychother Psychosom. 2005;74(5):288-94. [PMID: 16o88266]

[16] Masuda A, Kihara T, Fukudome T, Shinsato T, 
Minagoe S, Tei C. The effects of repeated thermal therapy for two patients with chronic fatigue syndrome. J Psychosom Res. 2005 Apr;58(4):383-87. [PMID: 15992574]

[17] Matsumoto S, Shimodozono M, Etoh S, Miyata R, Kawahira K. Effects of thermal therapy combining sauna therapy and underwater exercise in patients with fibromyalgia. Complement Ther Clin Pract. 2011 Aug;17(3):162-66. [PMID: 121742283]

[18] Matsushita K, Masuda A, Tei C. Efficacy of Waon therapy for fibromyalgia. Intern Med. 2008;47(16):1473-76. [PMID: 18703857]

[19] Chang Y, Liu YP, Liu CF. The effect on serotonin and MDA levels in depressed patients with insomnia when far-infrared rays are applied to acupoints. Am J Chin Med. 2009;37(5):837-42. [PMID: 19885944]

[20] Yamashita K. The effects of the Far-Infrared Ray (FIR) energy radiation on living body. In: T.E. Moschandreou (Ed.), Blood Cell - An Overview of Studies in Hematology, InTech, Rijeka, 2012; 271-302. [21] Vatansever F, Hamblin MR. Far infrared radiation (FIR): its biological effects and medical applications. Photon Lasers Med. 2012 Nov;4:255-66. [PMID: 23833705]

[22] Li K, Zhang Z, Liu NF, Feng SQ, Tong Y, Zhang JF, Constantinides J, Lazzeri D, Grassetti L, Nicoli F, Zhang YX. Efficacy and safety of far infrared radiation in lymphedema treatment: clinical evaluation and laboratory analysis. Lasers Med Sci. 2017 Apr;32(3):485-94. [PMID: 28127644]
[23] Barolet D, Christiaens F, Hamblin MR. Infrared and skin: friend or foe. J Photochem Photobiol B. 2016 Feb;155:78-85. [PMID: 26745730]

[24] Aragane Y, Higashino H. The "Enseki" sandbath: a novel, safe and effective far infrared bathing procedure for health. Photodermatol Photoimmunol Photomed. 2019 Jan;35(1):31-39. [PMID: 30120835]

[25] Mero A, Tornberg J, Mäntykoski M, Puurtinen R. Effects of far-infrared sauna bathing on recovery from strength and endurance training sessions in men. Springerplus. 2015 Jul 7;4:321. [PMID: 26180741]

[26] Kim HP. Lightening up light therapy: activation of retrograde signaling pathway by photobiomodulation. Biomol Ther (Seoul). 2014 Nov;22(6):491-96. [PMID: 25489415]

[27] Calles C, Schneider M, Macaluso F, Benesova T, Krutmann J, Schroeder P. Infrared A radiation influences the skin fibroblast transcriptome: mechanisms and consequences. J Invest Dermatol. 2010 Jun;130(6):1524-36. [PMID: 20130591]

[28] Kao MJ, Sheen LY. Effects of infrared and lowpower laser irradiation on cell viability, glutathione and glutathione-related enzyme activities in primary rat hepatocytes. J Formos Med Assoc. 2003 Jul;102(7):486-91. [PMID: 14517587]

[29] Halevy S, Lubart R, Reuveni H, Grossman N. Infrared $(780 \mathrm{~nm}$ ) low level laser therapy for wound healing: in vivo and in vitro studies. Laser Therapy. 1997;9(4): 159-64.

Keywords: Infrared; Near-infrared Rays; Mid-infrared Rays; Far-infrared Rays; FIR Sauna; FIR Blanket; IR Lamps; IR 